Anton Nijholt

Editor

\title{
Brain Art
}

Brain-Computer Interfaces for Artistic Expression

照 Springer 


\section{Editor}

Anton Nijholt

Human Media Interaction

Faculty of EEMCS

Universiteit Twente

Enschede, The Netherlands

ISBN 978-3-030-14322-0

ISBN 978-3-030-14323-7 (eBook)

https://doi.org/10.1007/978-3-030-14323-7

\section{(C) Springer Nature Switzerland AG 2019}

This work is subject to copyright. All rights are reserved by the Publisher, whether the whole or part of the material is concerned, specifically the rights of translation, reprinting, reuse of illustrations, recitation, broadcasting, reproduction on microfilms or in any other physical way, and transmission or information storage and retrieval, electronic adaptation, computer software, or by similar or dissimilar methodology now known or hereafter developed.

The use of general descriptive names, registered names, trademarks, service marks, etc. in this publication does not imply, even in the absence of a specific statement, that such names are exempt from the relevant protective laws and regulations and therefore free for general use.

The publisher, the authors and the editors are safe to assume that the advice and information in this book are believed to be true and accurate at the date of publication. Neither the publisher nor the authors or the editors give a warranty, expressed or implied, with respect to the material contained herein or for any errors or omissions that may have been made. The publisher remains neutral with regard to jurisdictional claims in published maps and institutional affiliations.

This Springer imprint is published by the registered company Springer Nature Switzerland AG The registered company address is: Gewerbestrasse 11, 6330 Cham, Switzerland 


\section{Foreword}

Anton Nijholt meets the pivotal need of charting the multiple ways in which artists have strategically challenged existing uses of EEG technology while unveiling its aesthetic and social implications. The term Brain Art has come to be associated with the use of Brain-Computer Interfaces (BCI) for artistic expression. It relies on the transmutation of neural signals into realms of sounds and images that render the internal workings of the mind perceptible.

A cornerstone of my career as an artist has been the exploration of what is now known as BCI, brain-computer interface. When I first heard the term, I thought it meant Brain Communication Interaction because that was what I had been working on for so long. In the early 1970s, after experimenting with an alpha wave feedback unit, I sought to create an internal and external video portrait of two people by dissolving images of their brain wave oscillations over their faces as their interaction was being simultaneously videotaped. What intrigued me was showing what often happens beneath the surface as people communicate with each other - at invisible brain level and at gestural level. I began concentrating on expressing visually the synchronous and asynchronous relations established between the brainwaves of people engaged in nonverbal communication. I invited participants in this work to engage in imaginative telepathic experimentation while embracing improvisation and indeterminacy. BCI allowed me to transcend the constraints of linguistic communication.

In 1973, together with collaborator systems engineer, Mike Trivich, we created conceivably the first BCI for two people to communicate nonverbally and telepathically via a visual feedback display. Our tools were a Grass Valley EEG connected to a DEC PDP 11 computer and a Heathkit 2 channel oscilloscope, assembled by Mike. We were expected to provide measurable outcomes of brain-to-brain communication upon being granted access to the use of an EEG machine and we fulfilled our promise. I continued to explore the realm of nonverbal communication through the 1980s and into the 1990s when I created the first interactive, multi-participant web-streaming platform in collaboration with Anatole Shaw. Since this time, my work with BCI has continued to expand, encompassing heart rate monitoring coupled with long used audio feedback and the Brain Wave Drawing Game. 
Flora Lysen's insightful observation in this collection- "The interface is the work" - is of particular interest to me as it has been fundamental to my own BCI endeavors. It gives us a useful entry point into examining how the medium shapes the social and aesthetic attributes of interpersonal exchanges, and the significance communicated by an artwork that has a technical interface as an essential component.

Artists are the clairvoyants in our society. When they embrace technology as a methodology, they make it visible to a public that has little direct contact with the daily work of scientists. The scientific rigor of artistic BCI has been questioned, but the true value of artists' use of this technology lies in the exploration of the epistemological, emotive, and educational impact of such interfaces. For BCI artists, the goal is always to move beyond the quantitative assessment of the impact of a technological apparatus.

BCI art is grounded in a shared experience of joy and creativity. When artists embrace technology, no matter how rigorous their process, their objective is the creation of an affective space meant to surpass self- or socially imposed boundaries between individuals. Artists are impresarios of technology!

Per Laura Jade in this anthology, we are "hybrid artists." Our work can only be understood through the interaction of artists, technology, and audience. Our passion fills that space and invites participation. Our dependence on scientists for our tools is a love affair that brings both parties closer together and inspires new and more complex collaborations.

Artists deploy BCI technology because it has the ability to render perceptible the inner workings of our deepest emotions. BCI always implies a process of externalization. It is deeply democratic in its ambitions: both demystifying technology and facilitating shared experiences. BCI artists rarely create in isolation. For them, the technological apparatus is foremost a tool of communication-whether between individuals or a multitude.

In editing this collection, Anton Nijholt has performed an invaluable service to scientists, the public and the worldwide creative community whose art finds its expression through a Brain-Computer Interface. This first overview of a field with half a century of groundbreaking collaborations and creations will be a precious guide as we adapt and expand new technologies like mobile-brain interfaces (MoBI), virtual reality (VR), and augmented reality (AR). This summing up is just the beginning!

New York

Nina Sobell

February 2019 


\section{Preface}

In recent years brain-computer interface $(\mathrm{BCI})$ technology has entered mainstream human-computer interaction (HCI) research for nonclinical applications. BCI has become part of multimodal interaction research as an additional interaction modality for a user of a technological system. BCI has also become part of research in which physiological data provide a system with information about a user's affective and mental state, making it possible to adapt the system, task, and interaction to a particular user.

Artists have been using BCIs for artistic expression since the 1960s. Artistic BCI applications date further back than assistive and clinical BCIs. Many years before Kamiya's and Vidal's influential papers on monitoring and controlling alpha activity and using brain activity for control and communication there were experiments by artists on musical composition, fine art, and other creative applications that required brain activity patterns as input. Early BCI music performances were performed by Alvin Lucier in 1965 and Richard Teitelbaum in 1967. A BCI drawing game was introduced by Nina Sobell in the early 1970s. In the same period, David Rosenboom started his investigations into the use of BCI in musical compositions and real-time performances. He published a wonderful collection on artistic and playful BCI experiments in 1976: "Biofeedback and the Arts: results of early experiments."

At the time artists started using BCI for artistic expression, there was hardly any research into signal processing, pattern recognition, machine learning, and (graphic) display possibilities. Indeed, and this was also mentioned by Vidal in 1973, BCI research was only possible using batch processing of data, rather than real-time processing of brain activity data.

Designers of artistic BCIs are often ahead of more traditional and patientoriented BCI researchers in their ideas on using BCIs in multimodal and multiparty contexts. Multiple users can be involved in an artistic BCI application. They can have an active role in making a BCI event possible or they can have a role as a 'passive' audience. Communication and control intentions or decisions can be detected from brain activity. This brain activity can be evoked by voluntarily paying attention to specifically designed external stimuli to which a user is exposed. 
However, BCI also makes it possible to detect changes in brain activity that have been evoked by conscious actions, for example, performing a mental calculation, imagining a movement, making the decision to relax, or reacting as if angry.

In games, entertainment, and artistic applications there is not always the need for robustness and efficiency that can be asked from other BCI applications. Shortcomings from BCI technology can perhaps be translated into interesting challenges to play and master a game or to create, modify, or experience a piece of BCI art or performance. HCI researchers' interest is increasing, because HCI and computer science have now entered application areas where efficiency is not the main goal or concern. Domestic or public space use of information and communication technology addresses issues that relate more to affect, comfort, family, community, or playfulness, rather than efficiency. In many everyday life situations, efficiency is an 'add-on'.

Interest in nonclinical applications of BCI research is now increasing. Currently, artists can make use of affordable BCI devices and software that does not require them to invest extensive time in getting the BCI to work or tuning it to their application. They may sometimes provoke traditional BCI researchers with their use of BCI hardware and software and their interpretation of brain signals. However, they certainly provide original thoughts about the use of BCI in applications and therefore pave the road for future BCI and HCI applications.

Users of artistic BCI technology can be artists who compose art in real time using BCI signals (usually in a multimodal and multimedia context), performers, audience members, or a full audience. Artists sometimes use reasonably cheap commercial BCI devices to work with or to perform. Or they design installations that require active or passive input from the brain of an individual user or the brains of multiple users or participants in artistic events. Those participants receive feedback from the artistic application that helps them to control their brain activity to create or modify pieces of interactive art. In addition to artistic BCI environments that allow users to play with and modify audio-visual landscapes, animations, and musifications, there are examples of BCI control of instruments and tools for artistic expression and exploration. For example, a BCI-controlled computer painting tool. Adaptive musical interfaces based on a user's brain state have also been introduced.

In this book, we look at current (research) activities in BCIs for artistic expression and to identify research areas that are of interest for both BCI and HCI researchers as well as for artists/designers of BCI applications. More generally, the book is intended for HCI and BCI researchers who are interested in nonclinical BCI applications, in particular, those BCI applications that invite users to interact, play, and to be creative, using BCI. The book addresses an audience that is interested in research that is focused on nontraditional and challenging interactions using BCI as a channel that allows artistic expression of moods, emotions, and other outlets of expressed creativity.

This book grew from the contributions of many colleagues to research activities I co-organized. Together with Hayrettin Gürkök, there was a 2013 paper on affective brain-computer interfaces for artistic expression presented at an affective computing conference. Before that, we used to work on BCI and games. A special issue 
of the Taylor \& Francis BCI journal on artistic brain-computer interfaces, edited by Chang S. Nam and me, appeared in 2015. It was great to meet David Rosenboom when he performed, assisted by Tim Mullen, at the Whitney Museum of American Art in New York in May 2015. A workshop on artistic brain-computer interfaces was organized at the 2016 Asilomar meeting on brain-computer interfaces. Additionally, I was happy to meet Nina Sobell (see picture) at the 2017 Brain on Art conference in Valencia organized by Jose L. Contreras-Vidal. A Handbook on BCI, also from Taylor \& Francis and edited by Chang S. Nam, Fabien Lotte and me, with many chapters devoted to nonclinical BCI applications appeared in 2018. In the same year, I organized a workshop at the CHI 2018 conference in Montreal, Canada on BCI for artistic expression. The co-organizers were Rob Jacob, Marvin Andujar, Grace Lesley, and Beste Yuksel. This book would not have been possible without the help of all the people mentioned here.

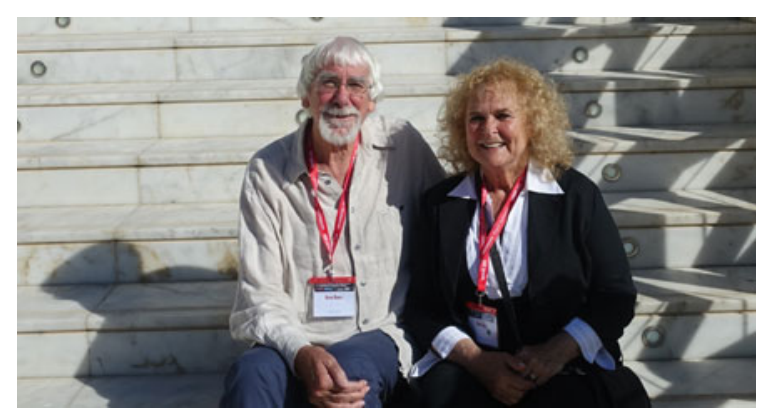

Enschede, The Netherlands

Anton Nijholt

February 2019 


\section{Contents}

1 Introduction: Brain-Computer Interfaces for Artistic

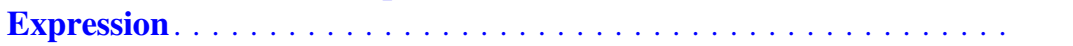
Anton Nijholt

Part I History, State of the Art, and Developments of Brain Art

2 The Interface Is the (Art)Work: EEG-Feedback, Circuited Selves and the Rise of Real-Time Brainmedia (1964-1977) . . . . . . . . . . 33 Flora Lysen

3 Brain-Computer Interfaces in Contemporary Art:

A State of the Art and Taxonomy Mirjana Prpa and Philippe Pasquier

4 More Than One-Artistic Explorations with Multi-agent BCIs . . . 117 David Rosenboom and Tim Mullen

5 Evaluating BCI for Musical Expression: Historical Approaches, Challenges and Benefits . . . . . . . . . . . . . . . . . . . . . 145 Duncan A. H. Williams

Part II Exploring Our 'Self' with Brain Art

6 Using Synchrony-Based Neurofeedback in Search of Human Connectedness .

Suzanne Dikker, Sean Montgomery and Suzan Tunca

7 EEG KISS: Shared Multi-modal, Multi Brain Computer Interface Experience, in Public Space . . . . . . . . . . . . . . . . . 207 Karen Lancel, Hermen Maat and Frances Brazier

8 New Ways of Knowing Ourselves. BCI Facilitating Artistic Exploration of Our Biology . . . . . . . . . . . . . . . . . . . . . . . . . 229 Laura Jade and Sam Gentle 
Part III Your Brain on Art: Perceiving, Understanding, and Creating

9 Understanding Perceptual Experience of Art Using Mobile Brain/Body Imaging . . . . . . . . . . . . . . . . . . . . . . . 265

Zakaria Djebbara, Lars Brorson Fich and Klaus Gramann

10 Your Brain on Art: A New Paradigm to Study Artistic Creativity Based on the 'Exquisite Corpse' Using Mobile Brain-Body Imaging .

Jesus G. Cruz-Garza, Girija Chatufale, Dario Robleto and Jose L. Contreras-Vidal

11 Self-conscience/Physical Memory: An Immersive, Kinetic Art Installation Driven by Real-Time and Archival EEG Signals 309 Eric Todd, Jesus G. Cruz-Garza, Austin Moreau, James Templeton and Jose Luis Contreras-Vidal

\section{Part IV Using Brain Art in Therapy}

12 Advancing the Rehabilitative and Therapeutic Potential of BCI and Noninvasive Sensing Systems

Stephanie M. Scott, Chris Raftery and Charles Anderson

13 BCI-Based Expressive Arts: Moving Toward Mind-Body

Alignment

Rainbow Tin Hung Ho, Sunee H. Markosov, Nathan Sanders and Chang S. Nam

Part V Brain Art: Control, Tools, Technology, and Hacking

14 Brain-Controlled Cinema

Richard Ramchurn, Sarah Martindale, Max L. Wilson, Steve Benford and Alan Chamberlain

15 The Making of Brain Painting-From the Idea to Daily Life Use by People in the Locked-in State Andrea Kübler and Loic Botrel

16 Methods and Tools for Using BCI with Augmented and Virtual Reality Felix Putze

17 The BR4IN.IO Hackathons

Christoph Guger, Brendan Z. Allison, Martin Walchshofer and Sarah Breinbauer 